\title{
A Measurement Method for College Librarian Performance Based on Neural Network
}

\author{
Wang Ping \\ Library of Hunan Institute of Science and Technology \\ Yueyang, Hunan, China \\ Hlwp318@163.com
}

\begin{abstract}
Librarian performance measurement is an important work for college libraries. It is of great significance for library management work. In this study, the measurement index system of Librarian performance is discussed and established firstly. Then, an improved BP algorithm with two times adaptive adjustment of learning parameters is applied in librarian performance measurement. A measurement method for college librarian performance based on BP neural network is proposed. The illustrational results show that we can realize a fast and accurate measurement of college librarian performance by this method. It is helpful for college libraries to promote the service quality and efficiency.
\end{abstract}

Keywords- Collegee Library; Librarian Performance Measurement; Neural Network; Integrated Measurement; Intelligent Method

\section{INTRODUCTION}

Performance measurement[1] means to measure whether employees' work activities and work results are consistant with organization's expectation or not in the given period. For college libraries, librarian performance measurement is one process of their management, and it is a significant work. Measuring librarians work effects by effective and objective standards scientifically, their basic qualities and work efficiency can be improved. For the purpose of establishing a measurement method for college librarian performance, the measurement index system of librarian performance will be discussed in this study, and neural network will be introduced in college librarian performance measurement. An intelligent method to measure librarian performance based on neural network will be proposed.

\section{MEASUREMENT INDEX SYSTEM OF COLLEGE LIBRARIAN PERFORMANCE}

In order to establish the measurement index system of college librarian performance, we must consider many factors. Combined with the actual performance management situation of domestic college libraries, the basic framework of the measurement index system of college librarian performance can be formed. The measurement index system[1,2,3,4] should include four areas,they are basic quality, operational capacity, work behavior and work performance. There are 12 specific measurement indexes, as Figure1 shows.

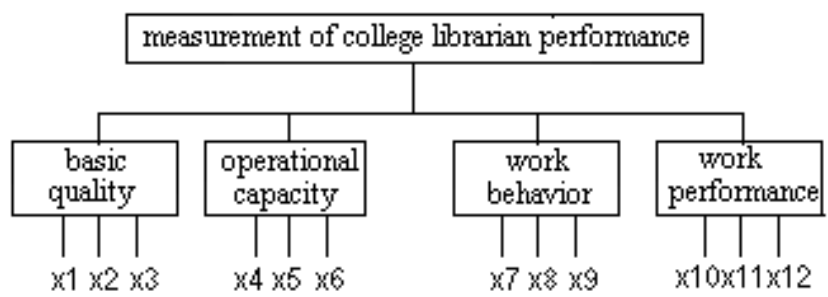

Figure 1. The measurement index system of college librarian performance

Where, X1, X2 and X3 denotes moral training, knowledge level and team cooperation consciousness respectively. X4, X5 and X6 denotes professional skills, management ability and innovation ability respectively. X7, X8 and X9 denotes work discipline, work efficiency and work activity respectively. X10, X11 and X12 denotes work quantity, work quality and work results respectively.

\section{Performance Measurement of College LIBRARIAN BASED ON NEURAL NETWORK}

\section{A. An Improved BP Neural Network Algorithm}

Neural network is a complicated network system that can realize parallel disposing and nonlinear transformation for information by simulating the way of human cerebral nerves to dispose information. It has a favorable ability to learn itself, adapt itself, associate and recollect, process parallel etc.. In all kinds of neural networks, BP neural network algorithm[5,6,7,8] is a typical delegate and has been applied widely. From the point of structure, BP neural network belongs to the typical forward-propagation network. It is made up of input layer, output layer and some hiding layers, in which the nodes of adjacent layers are connected wholly and the nodes of the same layer are not connected. The typical BP neural network is a three-layer network made up of input layer, output layer and a hiding layer. This is the most fashionable BP neural network. Error backpropagation algorithm is adopted in the course of BP neural network's training, its shortened form is BP algorithm. BP algorithm is a kind of training algorithm with tutor, it is virtually a kind of simple static algorithm for seeking the optimal by grads descending. Weight $w(n)$ is modified only according to the direction of negative grads at the time of $n$, and the former experience is not considered. The speed of convergence is very slow because of the frequent 
surging or falling into local minimum in the course of training. In order to avoid BP neural network's surging and falling into local minimum in the course of training, a method of additional momentum is adopted. This method means to add an item in proportion to the former variety to current variety of all weights and thresholds, and the new weights and thresholds will be produced according to the reverse transmission. The regulating formulas with additional momentum of weights and thresholds are defined as:

$$
\begin{aligned}
& \Delta w_{j t}(k+1)=(1-m c) \cdot \alpha \cdot d_{t}^{k} \cdot b_{j}+m c \cdot \Delta w_{j t}(k) \\
& \Delta \theta_{t}(k+1)=(1-m c) \cdot \alpha \cdot d_{t}^{k}+m c \cdot \Delta \theta_{t}(k)
\end{aligned}
$$

Where, $k$ denotes training times, $\alpha$ denotes training ratio, $m c$ denotes momentum factor, $0<\alpha<1, \quad 0 \leq m c<1$, $\alpha$ and $m c$ are decided by one's experience.

However, it is easy for traditional BP neural network algorithms to fall into surge and the local optimal, and its convergence speed is slow. So, an improved BP algorithm with two times adaptive adjustment of learning parameters is used to measure college librarian performance. The basic idea of this improved BP algorithm is:

Step1: Iinitialize the connection weights and thresholds by random numbers between 0 and 1 ;

Step2: Select a learning sample randomly for the network;

Step3: Calculate the output of hidden layer units and output layer units;

Step4: Calculate output error $E(t)$;

Step5: Calculate the general error of output layer units and hidden layer units;

Step6: Adjust learning rate $\eta$ and momentum factor $\alpha$ according to formula (3) and (4), thenadjust connection weights and thresholds.

$$
\begin{aligned}
& \eta(t+1)=\eta(t)+\varphi \cdot \eta(t), \alpha=\alpha ; \text { if } E(t) \leq E(t-1) \\
& \eta(t+1)=\eta(t)-\varphi \cdot \eta(t), \alpha=0 ; \quad \text { else }
\end{aligned}
$$

Step7: Select the next learning sample randomly for the network and return to step (3), till m learning samples trained over;

Step8: Calculate the maximum error $S E_{\text {max }}(N)$ of this learning course;

Step9: Judge error:

$$
\text { If } S E_{\max }(N) \leq e \text {, learning over; }
$$

else, go to next step;

Step10: Adjust the optimal control value $e$ :

$$
\begin{aligned}
& \text { Let } \Delta S E_{\text {max }}(N)=S E_{\text {max }}(N)-S E_{\text {max }}(N-1) \\
& \Delta S E_{\text {max }}(N-1)=S E_{\text {max }}(N-1)-S E_{\text {max }}(N-2) \\
& \overline{\Delta S E_{\max }}=\left[\Delta S E_{\max }(N)+\Delta S E_{\max }(N-1)\right] / 2 \\
& \text { If } \overline{\Delta S E_{\max }}>\mathcal{E} \text {, then let } e=S E_{\max }(N) / 2 \text {; }
\end{aligned}
$$

else let $e=S E_{\max }(N)$.

Where, $\mathcal{E}$ is the convergence boundary value determined according to the accuracy requirement. $\overline{\Delta S E_{\max }}$ is the average value of the maximum error in Two recent learning.

Step11: Re-select a learning sample randomly and return to step (3), till $S E_{\max }(N) \leq e$;

Step12: Learning over.

\section{B. Function Module of the Measurement System of Librarian Performance}

The measurement system of librarian performance based on neural network is realized by Visual $\mathrm{C}++6.0$. The software architecture of system is formed by following four modules: data input module, data pre-processing module, neural network learning module, and neural network measurement module. The function of data input module is: obtain and input readers' measurement data of library service quality. Readers' measurement can be carried out by the way of questionnaire or online directly. The function of data pre-processing module is: change input measurement data into unitary data between 0 and 1 for the neural network to process. The function of neural network learning module is: train neural network using the selected training samples and obtain the optimal weights and thresholds. The function of neural network measurement module is: identify and classify the readers' measurement data by the optimal weights and thresholds of neural network, and output the measurement results.

\section{BP Neural Network Model for Librarian Performance Measurement}

There are 12 measurement indexes in measuring librarian performance, they are $x 1, x 2, \cdots, x 12$. Each of the measurement indexes has 5 measurement grades, they are excellent, good, moderate, poor and very poor. And the measurement target has the same 5 measurement grades too.

The values of measurement indexes are provided as: 1 means excellent, 2 means good, 3 means moderate, 4 means poor, and 5 means very poor. Based on considering all the circumstances, we obtain the learning sample set of neural network from the measurement data set of readers. In this study, twenty-four training samples are selected to train BP neural network. Some training samples are shown in TABLE I.

The BP neural network model for librarian performance measurement is formed as Figure 2 shows. The structure of neural network is 12-16-5, which means that the number of input layer nodes is 12, the number of output layer nodes is 5 and the number of hiding layer nodes is 16 .

\section{Training and Measuring of Neural Network}

In the course of the neural network's training, the parameters are designed as: $\varphi=0.1, \varepsilon=10^{-3}$. The selected training samples are used to train BP neural network. After 
trained 852 times, the neural network arrived at its convergence and $M S E=0.000080$.

After neural network's training, five samples which are not trained are offered for it to evaluate. The measuring samples and measurement results are shown in TABLE II and TABLE III.

The results in TABLE III show that although the five samples are not trained, the measurement results are all identical with the measurement targets. So, the neural network's ability to reason is strong, and it is able to realize the correct measurement for library service quality.

TABLE I. SOME TRAINING SAMPLES

\begin{tabular}{|c|c|c|c|c|c|c|c|c|c|c|c|c|c|}
\hline \multirow{2}{*}{ NO. } & \multicolumn{12}{|c|}{ Measurement Index } & \multirow{2}{*}{$\begin{array}{c}\text { Measurement } \\
\text { target }\end{array}$} \\
\hline & \multicolumn{12}{|c|}{$\times 1 \times 2 \times 3 \times 4 \times 5 \times 6 \times 7 \times 8 \times 9 \times 10 \times 11 \times 12$} & \\
\hline 1 & 1 & 1 & 1 & 1 & 1 & 1 & 1 & 1 & 1 & 1 & 1 & & excellent \\
\hline 2 & 1 & 1 & 1 & 1 & 1 & 1 & 1 & 1 & 1 & 1 & 2 & 1 & excellent \\
\hline 3 & 1 & 1 & 2 & 1 & 1 & 1 & 2 & 1 & 1 & 1 & 1 & 1 & good \\
\hline 4 & 1 & 1 & 1 & 1 & 2 & 1 & 2 & 2 & 1 & 1 & 1 & 1 & good \\
\hline 5 & 1 & 1 & 2 & 2 & 3 & 1 & 3 & 3 & 1 & 2 & 2 & 1 & moderate \\
\hline 6 & 1 & 2 & 1 & 2 & 3 & 3 & 2 & 2 & 1 & 2 & 3 & 3 & moderate \\
\hline 7 & 3 & 3 & 4 & 3 & 3 & 2 & 4 & 2 & 4 & 4 & 2 & 4 & poor \\
\hline 8 & 2 & 3 & 4 & 3 & 4 & 3 & 4 & 2 & 3 & 3 & 4 & 3 & poor \\
\hline 9 & 2 & 3 & 3 & 3 & 4 & 5 & 5 & 5 & 4 & 4 & 5 & 4 & very poor \\
\hline 10 & 3 & 3 & 4 & 3 & 5 & 4 & 5 & 5 & 4 & 3 & 2 & 4 & very poor \\
\hline
\end{tabular}

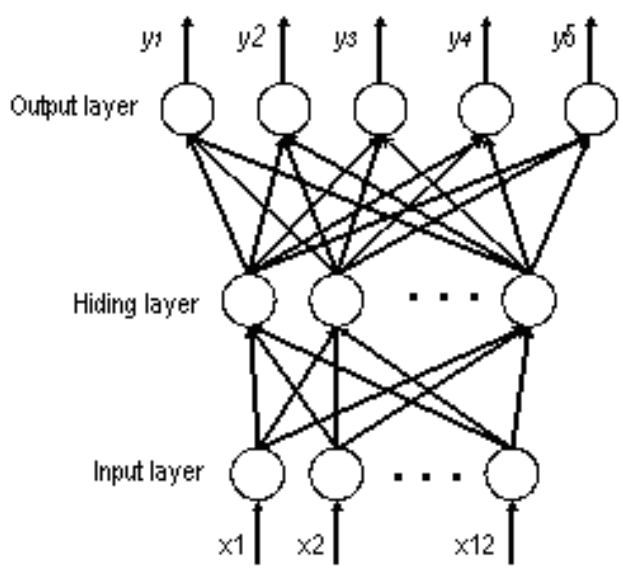

Figure 2. BP neural network model for librarian performance measurement

TABLE II. MEASURING SAMPLES

\begin{tabular}{|c|c|c|c|c|c|c|c|c|c|c|c|c|}
\hline \multirow{2}{*}{ NO. } & \multicolumn{11}{|c|}{ Measurement Index } & \multirow{2}{*}{$\begin{array}{c}\text { Measurement } \\
\text { target }\end{array}$} \\
\hline & \multicolumn{11}{|c|}{ x1 x2 x3 x4 x5 x6 x7 x8 x9 x10 x11 x12 } & \\
\hline 1 & 11 & 1 & 2 & 1 & 1 & 1 & 1 & 1 & 1 & 1 & 1 & excellent \\
\hline 2 & 11 & 2 & 1 & 2 & 1 & 1 & 1 & 1 & 2 & 1 & 1 & good \\
\hline 3 & 1 & 1 & 1 & 3 & 1 & 3 & 2 & 2 & 2 & 3 & 1 & moderate \\
\hline 4 & 2 & 2 & 3 & 4 & 2 & 4 & 3 & 4 & 3 & 3 & 4 & poor \\
\hline 5 & 4 & 5 & 3 & 4 & 4 & 5 & 5 & 3 & 4 & 5 & 4 & very poor \\
\hline
\end{tabular}

TABLE III. MEASUREMENT RESULTS

\begin{tabular}{c|c|ccccc}
\hline \multirow{2}{*}{ NO. } & \multirow{2}{*}{$\begin{array}{c}\text { Measurement } \\
\text { target }\end{array}$} & \multicolumn{5}{c}{ Actual output } \\
\cline { 3 - 7 } & & $\mathrm{y} 1$ & $\mathrm{y} 2$ & $\mathrm{y} 3$ & $\mathrm{y} 4$ & $\mathrm{y} 5$ \\
\hline 1 & excellent & 0.991850 & 0.000628 & 0.000885 & 0.004230 & 0.001125 \\
2 & good & 0.001357 & 0.986814 & 0.000928 & 0.000855 & 0.001215 \\
3 & moderate & 0.005525 & 0.007274 & 0.975863 & 0.000983 & 0.003278 \\
4 & poor & 0.004065 & 0.004665 & 0.001268 & 0.988585 & 0.006892 \\
5 & very poor & 0.002249 & 0.006185 & 0.004267 & 0.008292 & 0.978505 \\
\hline
\end{tabular}

IV. CONCLUSION

Based on the analysis of college librarian performance, the measurement index system of college librarian performance is established. An improved BP Algorithm, namely BP Algorithm with two times adaptive adjust of learning parameters is proposed and introduced in the measurement of college librarian performance measurement. A measurement model for college librarian performance is formed. As neural network has a strong self-learning and self-adapting function, the measurement system is intelligent. Examples show that this measurement method is not only feasible, but also is fully effective. It can provide strong support for us to measure college librarian performance objectively and reasonably.

\section{ACKNOWLEDGMENTS}

Support from the Science Foundation of Hunan Institute of Science and Technology under Grant No. 2011Y19 is gratefully acknowledged.

\section{REFERENCES}

[1] Zhao Long-gang, Lin Hong-jin. University Librarian Performance Evaluation Based on Fuzzy Comprehensive Evaluation. Chinese trade and economic Tribune,2012(8):48-50

[2] Ma Wen-qin. 360-degree performance evaluation and performance appraisal of college librarian. Library Journal,2012(3):21-22

[3] Yang Mei. Exploration on the Evaluation of librarian performance. Library Theory and Practice,2012(2):16-18

[4] Xu Zhong. Problems and Countermeasures in College Librarian performance measurement system. Library and Information Service,2009(11):36 39.

[5] Ma Rui. Principle of artificial neural network. China machine press, Beijing, 2010

[6] Wang Xiao-Ping, Cao Li-Ming, Genetic algorithm - theory, application and software realization, Xi'an Jiao tong University Press, Xi'an, 2002.

[7] Li Min-Qiang, Kou Ji-Song, Lin Dan, Li Shu-Quan, Basic principle and application of genetic algorithm, Science publishing company, Beijing , 2002.

[8] Wang Wei, Artificial neural network principle - the primer and application. Beijing aviation and aerospace university publishing company, Beijing. 1995. 